\title{
REINTERPRETANDO PAREDES: INTERACCIÓN E INTERCAMBIO DE INFORMACIÓN EN EL IBÁÑEZ MEDIO, PATAGONIA CENTRAL, CHILE
}

\author{
REINTERPRETING WALLS: INTERACTION AND INFORMATION EXCHANGE \\ IN THE MIDDLE IBÁÑ̃EZ RIVER, CENTRAL PATAGONIA, CHILE
}

Rosario Corderoa, Camilla Muñoz $z^{B}$ Diego Artigas ${ }^{c}$

En este trabajo se resumen los resultados del registro sistemático de diferentes sitios con arte rupestre en el sector medio del río Ibáñez, Región de Aysén (Patagonia central, Chile). A partir de la caracterización de los sitios, el análisis de las figuras, técnicas, frecuencias y las comparaciones con los grupos estilísticos definidos para el área del río Pinturas de la Patagonia central, se discute la idea de estilo, la teoría de intercambio de información y la noción de memoria colectiva, con el fin de acercarnos a la comprensión del comportamiento de los grupos que vivieron en esta zona durante el Holoceno.

Palabras clave: Arte rupestre, Patagonia, Estilo, Intercambio de información, Memoria colectiva.

This paper summarizes the results of the systematic recording of different rock art sites in the middle reaches of the Ibáñez River, in Aysén Region (Central Patagonia, Chile). Through a characterization of archaeological sites in the area, analysis of the rock art figures, techniques, and frequencies, and comparisons with previously-defined Patagonian stylistic groups, the authors discuss the notions of style, information exchange theory, and collective memory to reach conclusions about the behavior of the human groups that lived in this area during the Holocene.

Keywords: rock art, Patagonia, style, information exchange, collective memory.

\section{INTRODUCCIÓN}

El valle del río Ibáñez, ubicado en la Región de Aysén (Chile), se caracteriza por ser una zona con vientos predominantes que soplan desde el oeste y donde es posible observar una gran diversidad de paisajes, desde bosques tropicales a pastizales y arbustos situados cerca del río (Mena 1990, Mena \& Lucero 1998). Por razones investigativas, la cuenca del Ibáñez ha sido dividida en tres sectores: alto, medio y bajo (Mena \& Ocampo 1993), siendo el sector medio el que se extiende desde el río Manso hasta el río Claro (fig. 1).

Las investigaciones en el área de estudio han permitido establecer una ocupación de la zona que se caracteriza por presentar diversos sitios arqueológicos con presencia de arte rupestre (Bate 1970, 1971; Mena 1989, 1990; Mena \& Lucero 1998; Lucero \& Mena 2000; Artigas \& Muñoz 2012; Muñoz 2013), lo que nos permite entrever el desarrollo de este tipo de manifestaciones culturales como una tradición de extensa cronología (Mena et al. 2013).

\footnotetext{
A Rosario Cordero, Universitat Autònoma de Barcelona, Vila i Vilà 95, 5-2, Barcelona, España. E-mail: rosariocorderof@gmail.com

B Camila Muñoz, Université Paris 1 Panthéon-Sorbonne, 2 Square Marcel Toussaint, París, Francia.

E-mail: camila.munoz.soto@gmail.com

c Diego Artigas, Universidad SEK, Fernando Manterola 0789, Providencia, Santiago, Chile. E-mail: diego.artigas@zonavirtual.usek.cl
} 


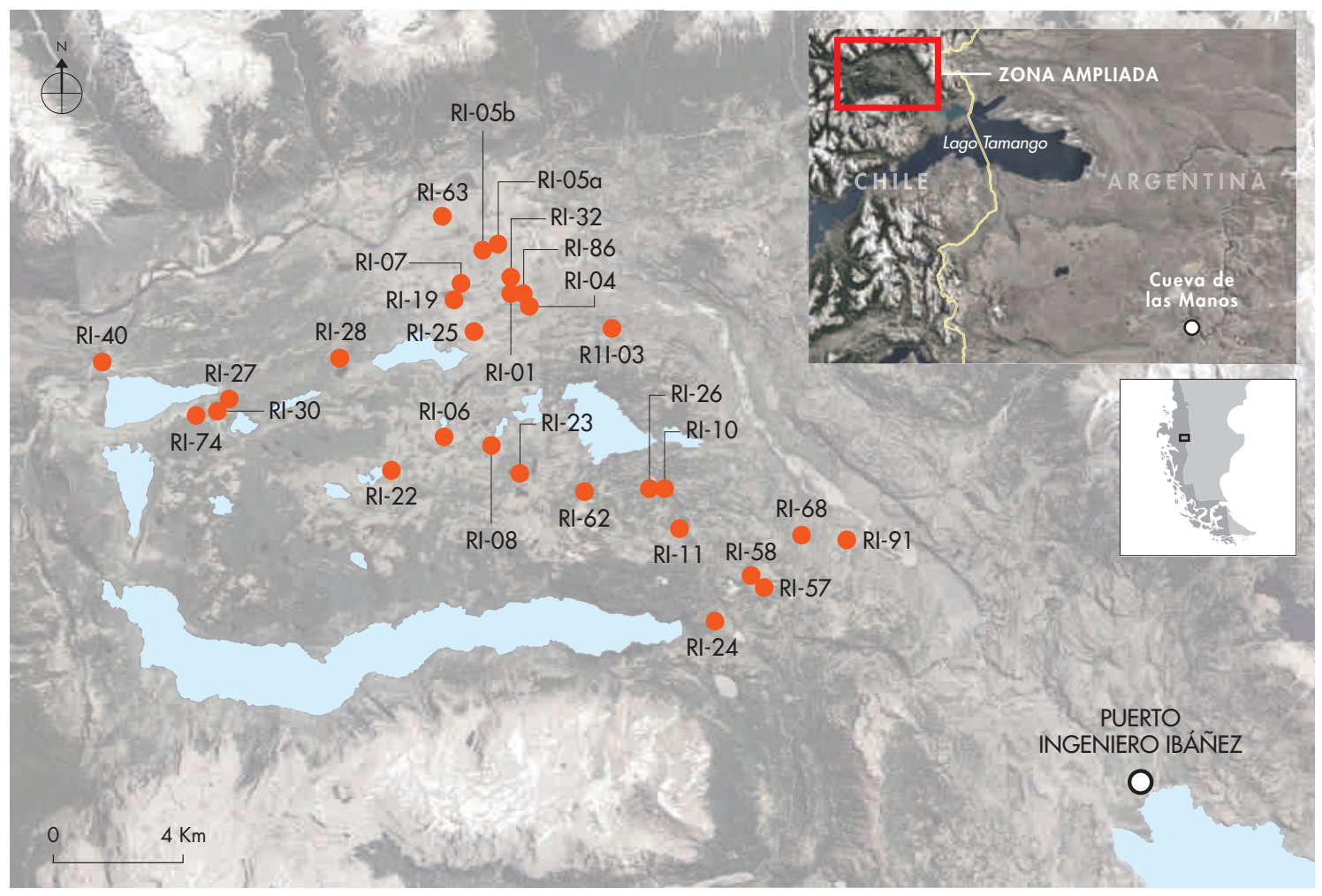

Figura 1. Área de estudio y sitios con arte rupestre registrados. Figure 1. Area of study showing the rock art sites recorded.

El estudio de los yacimientos con arte rupestre identificados en el Ibáñez medio ha dado como resultado el registro sistemático de 29 sitios, permitiendo conocer cómo se movían los antiguos habitantes de este territorio y, a la vez, proponer interpretaciones considerando patrones en común, temáticas y técnicas, entre otros aspectos.

\section{EL ARTE RUPESTRE EN EL CONTEXTO DE LA ARQUEOLOGÍA DEL IBÁÑNEZ MEDIO}

La primera evidencia de pinturas rupestres en el extremo sur de Chile la realizó Bird (1993) a principios de los años treinta del siglo $\mathrm{xx}$ y luego fueron descritas por Laming-Emperaire (1966), ambos refiriéndose solo a Magallanes. Sin embargo, en el área de estudio, fue Bate $(1970,1971)$ quien registró numerosos sitios con pinturas rupestres.

Una década después, Mena (1983) reanudó la investigación en la región y tras las primeras excavaciones sistemáticas en la parte baja del valle del río Ibáñez, espe- cíficamente en el sitio Cueva de las Guanacas, identificó dos niveles culturales, de los cuales el más temprano data de $5340+/-180 \mathrm{AP}$, correspondiente al nivel medio (Mena 1983, Fuentes \& Mena 2010). ${ }^{1}$ También destacó la presencia de pinturas en las paredes de la cueva, específicamente motivos de guanacos, además del hallazgo de una concentración de pigmento rojo (regolito compuesto por hematita y cuarzo) en el nivel medio, lo que sugiere que la datación podría corresponder al momento en que se realizaron las imágenes. Posteriormente, en 1983, en las excavaciones en el sitio RI-18 se hallaron pinturas compuestas por motivos de manos (Berquist et al. 1983).

La cronología de las ocupaciones del río Ibáñez sitúa las primeras evidencias en $5850 \pm 30 \mathrm{AP}$ (sitio Las Mellizas, capa 4, carbón vegetal UGAMs 13214 AMs, Mena \& Lucero 2015), asociadas a poblaciones que provienen posiblemente de la vertiente oriental trayendo una poderosa tradición de arte rupestre (Mena \& Lucero 2015), producción que pasará a ser una de las características de la ocupación en la zona (Bate 1970, 1971).

En este sentido, es posible observar que, en ambas áreas, las ocupaciones en el Holoceno Medio presentan 
semejanzas. Sin embargo, existe una cronología muy distante en relación con el inicio de la producción del arte rupestre de la vertiente occidental en comparación con las ocupaciones de la Patagonia argentina, donde se ha datado el comienzo de la práctica del arte rupestre en el río Pinturas alrededor del 9000 AP (Gradin et al. 1979, Gradin et al. 1987, Carden 2009, Aschero 2012). Por estas razones, Mena (2016a) considera que las ocupaciones del río Ibáñez corresponderían a sistemas sociales particulares espacialmente restringidos. Esta delimitación espacial, incluyendo las características del arte rupestre en la zona, ha permitido interpretaciones que sugieren que los grupos humanos se organizaron como unidades sociales pequeñas que se movían al interior del valle en temporadas con mejor clima para aprovechar ciertos recursos de la zona, por ejemplo, el huemul, observado en sitios como RI-22 (Mena 1992, Velásquez \& Trejo 2003) y RI-23 (Mena \& Lucero 2015).

El estudio del arte rupestre había quedado relegado a aproximaciones meramente descriptivas en estos trabajos, especialmente respecto a su posición y orientación (Lucero \& Mena 2000), y no como un elemento integrador del paisaje. Esto provocó que los sitios de arte rupestre no fueran incluidos en las interpretaciones regionales, ignorando su capacidad como material arqueológico e indicador cultural (Bate 1970, 1971; Mena 1989, 1990; Lucero \& Mena 1994, 2000). Lo anterior se refleja en el bajo número de excavaciones en sitios con arte rupestre, haciendo difícil establecer asociaciones entre los materiales encontrados en excavaciones y pinturas.

No obstante, en los últimos años las investigaciones del arte rupestre se han integrado a la discusión ya existente, basada en los sitios estratigráficos y los análisis de las materialidades más clásicas, como la lítica y los restos zooarqueológicos (Artigas \& Muñoz 2012, Muñoz 2013, entre otros). Esto ha generado una nueva visión de los modos de ocupación del área, por lo cual la definición inicial planteada por Mena (2016a), como sistemas cerrados, se ve en parte contrastada con los análisis de las distintas manifestaciones culturales. Esto nos permite un acercamiento diferente considerando poblaciones que pueden ser parte de sistemas más amplios de movilidad, abarcando también las áreas del Ibáñez bajo, e incluso con el sector argentino (Méndez \& Reyes 2006, Mena et al. 2013, Mena \& Lucero 2015, Mena et al. 2015, Gómez 2016).

\section{Cronología tentativa de las representaciones rupestres presentes en el río Ibáñez}

Actualmente no se cuenta con fechados directos de las pinturas presentes en el Ibáñez, aun cuando fueron analizadas 28 muestras de pigmentos extraídas directamente de las representaciones halladas en diferentes sitios. Desafortunadamente, las muestras no contaron con suficiente material orgánico para poder realizar dataciones (Steelman 2014), por lo que se cuenta únicamente con indicios indirectos correspondientes a restos de pigmentos identificados en estratigrafía, específicamente para los sitios RI-16 y RI-23.

En cuanto a RI-23, se identificaron restos de pigmentos en la capa IV, que tras su análisis a partir de espectroscopia Raman, se logró determinar que corresponden a hematita (Mena et al. 2013), además de identificar en la unidad 15A, capa IV, un guijarro que en una de sus caras presentaba posibles restos de pigmento rojo. A partir de lo anterior, considerando que los motivos presentes en el sitio corresponden únicamente a improntas de manos en color ocre, descartando los manchones (Muñoz 2013), se obtuvieron dos fechas sobre carbón vegetal correspondientes a $5850 \pm 30$ y $5820 \pm 25$ años AP (UGAMS 13214 AMS y UGAMs 13217, Mena \& Lucero 2015), además de una datación de la base de la unidad 15A consistente en 2370 \pm 25 años AP (Ugams 13215 AMs, Mena 2016b).

En cuanto a RI-16, a partir de las excavaciones realizadas en la década de 1980, se logró recuperar 513 g de pigmento rojo en el nivel cultural II (Mena 1983), denominado posteriormente como nivel inferior (Labarca et al. 2008), el cual, al ser analizado, se determinó su estrecha relación con la pintura empleada en las representaciones presentes en el sitio (Mena 2000). Cabe destacar que, en dicho yacimiento, además de identificar figuras zoomorfas (guanacos), también se registraron motivos caracterizados como geométricos simples en la misma tonalidad (Muñoz 2013).

Por lo anterior, al relacionar la presencia de pigmento en estratigrafía y las fechas obtenidas asociadas al nivel cultural II, específicamente de la base de la capa 6 y en la cumbre de la capa 7, correspondientes a 4720 \pm 60 (Beta 103159) y $5340 \pm 190$ (Beta 76356, Mena 1983, 2000), se puede asociar indirectamente la realización de arte rupestre a dichos momentos ocupacionales.

Sin embargo, y de acuerdo con lo recién expuesto, observamos tentativamente la realización de diferentes 
motivos de forma sincrónica durante los momentos iniciales de ocupación en el río Ibáñez (improntas de manos, zoomorfos, geométricos simples), los cuales pudieron haberse extendido a momentos posteriores de la secuencia, teniendo en cuenta la presencia de hiatos de ocupación entre 1000 y 1400 años AP y 2400 y 4800 años AP (Mena 1983, Mena 2000, Mena et al. 2015, Mena \& Lucero 2015).

Cabe destacar que lo anterior se basa en inferencias iniciales, debido a que los estudios en el Ibáñez se han centrado en el análisis de otras materialidades, además de no contar con fechas directas sobre el arte rupestre.

\section{Grupos estilísticos propuestos previamente en el arte rupestre de la Patagonia central}

El estudio del arte rupestre del sector del río Pinturas (Argentina) ha marcado fuertemente el conocimiento de esta manifestación en la Patagonia central. Estos trabajos poseen en su mayoría un fuerte enfoque histórico-cultural. Esto ocurre especialmente al momento de explicar y distinguir los distintos motivos y definir los diferentes grupos estilísticos, considerando a estos como la "agrupación de semejanzas temáticas, de ejecución y/o entre figuras animales, humanas y signos geométricos simples que ocurrían dentro del amplio repertorio de representaciones" (Aschero 2012: 5), además de los fechados radiocarbónicos indirectos y la superposición de las representaciones.

Los motivos existentes fueron clasificados inicialmente en cuatro grupos generales (Gradin et al. 1979, Gradin 1983, Gradin \& Aguerre 1994). Posteriormente se incluyeron dos más, los que fueron utilizados recurrentemente en la caracterización del arte rupestre en la zona del río Ibáñez (Lucero \& Mena 1994, 2000), sin considerar la nueva revisión de los grupos estilísticos (Aschero 1996, 2012) planteada inicialmente para el área del río Pinturas, lo que generó algunos problemas en su análisis. Uno de estos motivos corresponde a la relación del arte rupestre con la ocupación estratigráfica de los sitios, ya que la definición de los grupos estilísticos no siempre coincide con la caracterización cultural evidenciada en las excavaciones, generando gran debate sobre este tema (Boschín 1994).

Por otro lado, la caracterización de los estilos no detalla de manera particular el problema que generan las improntas de manos (en positivo y negativo) y las figuras geométricas simples, dado que estos diseños se asocian indistintamente con grupos estilísticos diferentes. Esto indica que algunos motivos del arte rupestre habrían estado presentes desde el inicio de esta práctica en la Patagonia hasta tiempos tardíos y, a la vez, dependido de la identidad y las tradiciones de los distintos grupos que habitaron la zona (Boschín 1994).

Conviene aclarar que las distancias temporales en el inicio de la producción del arte rupestre que se dan entre ambas zonas (río Pinturas y río Ibáñez) son lejanas, por lo que, plantear relaciones entre motivos y formas, debiera tratarse con cautela, ya que la producción simultánea de esta manifestación en ambas zonas podría asociarse recién con momentos tardíos de ocupación efectiva de los espacios (Borrero 1989-1990; Aschero 2012). En otras palabras, el inicio de las prácticas relacionadas con el arte rupestre en el río Pinturas están datadas hacia el 9000 AP (Gradin et al. 1987), mientras que, en el río Ibáñez, habrían aparecido unos 3000 o 4000 años más tarde, según las fechas obtenidas en las excavaciones arqueológicas del sector. Aun cuando se aprecian algunas similitudes formales en los motivos, es necesario tener una visión crítica sobre las semejanzas que se observan en el arte rupestre de ambas zonas.

\section{El concepto de estilo}

Llegados a este punto, creemos necesario integrar en nuestra discusión el concepto de "estilo", altamente explotado en los estudios de arte rupestre y en la arqueología. Entendido como variación formal (Sackett 1982, Hodder 1990, Wiessner 1990, Hegmon 1992), el "estilo" ha sido considerado como las características representativas de un período o región en particular, con una temporalidad y patrones espaciales definidos a partir de la regularidad (Conkey \& Hastorf 1990).

Las diferencias existentes respecto de la noción de este concepto en la bibliografía se refieren a la necesidad de establecer criterios válidos para la definición de los distintos estilos que se podrían reconocer, las variables que pueden condicionarlos, o qué tipo de información es susceptible de ser transmitida a través de los rasgos estilísticos. Las concepciones acerca del estilo son diversas y se han relacionado con los fenómenos sociales, incluyendo la manipulación política, la ideología y la negociación de las estrategias sociales (Earle 1990). También puede entenderse como formas de producción y el uso de los materiales, basados en 
patrones y estructuras socialmente aprehendidos, que pueden ser representados por una serie de atributos visuales que actúan como un medio a través del cual los seres humanos dan sentido a su mundo y generan un significado cultural (Conkey 2006).

Sackett $(1982,1985,1986)$ sostiene que el estilo implica una elección entre diferentes alternativas funcionalmente equivalentes, como una forma de expresar una manera específica e individual de hacer las cosas en un determinado momento y lugar. De acuerdo con McDonald (2000: 54), el estilo "is the particular way of doing or producing material culture which signals the activity of a particular group of people who distinguish themselves from other, similarly constituted groups". En este sentido, el estilo se puede utilizar como un medio de articulación de la identidad de un grupo del pasado, lo que está directamente relacionado con la búsqueda de evidencias que reflejen una identidad social.

Según Troncoso (2003), en los estudios de arte rupestre el estilo se puede expresar a través de la generación de una serie de motivos que se rigen por ciertas reglas: las técnicas específicas para la producción de figuras; uso de un soporte específico; una localización espacial particular y una articulación específica de figuras en el interior de los paneles o conjuntos. Desde esta perspectiva, el estilo puede ser entendido como un sistema integral de normas donde la producción de todo el arte rupestre opera dentro de un sistema más amplio. En lugar de definir reglas estrictas, el concepto permite la amplitud de la creación basada en supuestos compartidos (Troncoso 2003). Su definición de estilo es particularmente útil en la discusión del arte rupestre ya que comprende diferentes niveles. Esta es la modalidad que hemos asumido para nuestra comprensión del estilo.

Dicho esto, nos encontramos con una característica única del arte rupestre que le permite ocupar un mismo lugar en distintas épocas. Esta característica es la inmovilidad, que convierte el espacio en un elemento unificador del estilo en la medida en que genera una base para la comunicación de información simbólica, a la vez que establece límites para la presentación de una misma información.

El mapeo de la distribución geográfica de los sitios de arte rupestre ha sido un método comúnmente empleado para el examen de los límites territoriales y las interacciones sociales entre grupos vecinos, con el fin de entender las continuidades y discontinuidades espaciales (Domingo-Sanz et al. 2008, McDonald 2000, entre otros). Bajo esta premisa, McDonald (2000) se refiere a que cierta variabilidad artística puede ser generada a través del estilo, lo que permite la discusión de intercambio de información en la arqueología.

\section{Intercambio de información y estilo}

Considerando lo expuesto en los párrafos anteriores, creemos que, en relación con las identidades sociales de los grupos que habitaban el Ibáñez medio, se hace necesario hacer hincapié en cómo la teoría del intercambio de información (Wobst 1977) ha relacionado el mantenimiento de las distinciones sociales entre los grupos humanos y su vinculación con el estilo (Hodder 1978; Wiessner 1983, 1984, 1990; Gamble 1990; Smith 1992, 1994; McDonald 2000).

Esta teoría (Wobst 1977) ha sido una contribución fundamental a los estudios que han tratado de comprender la interacción social de los grupos del pasado, ya que entiende el rol del estilo en un sistema cultural específico, es decir, como un medio de transmisión de información acerca de la identidad individual y social. $\mathrm{Al}$ mismo tiempo, supone que los objetos (móviles o inmóviles) participan en procesos de intercambio de energía, materia e información, por lo tanto, entiende el estilo como un fenómeno multidimensional y dinámico (Wobst 1977).

De acuerdo con Wobst (1977), el estilo es una forma de exposición social que codifica la información no solo acerca de la identidad individual, sino también en relación con la pertenencia a un grupo social, las creencias religiosas y la ideología. De esta manera, el contacto entre el emisor y el destinatario del mensaje y la visibilidad de los objetos adquieren especial importancia, dado que los códigos entre ambos deben ser relativamente conocidos para que el mensaje sea decodificado con éxito. Esto sugiere que existen medios materializados en las pautas de estilo que ayudan a mantener la comunicación entre grupos que pueden tener un contacto verbal bajo o nulo. En otras palabras, la eficiencia del estilo puede reducir la dificultad de comunicación entre diferentes grupos humanos en la medida en que las pautas sean conocidas.

Por otro lado, la teoría del intercambio de información se basa en el impacto potencial de las condiciones ambientales, el tamaño de los grupos, las redes sociales y la variabilidad estilística dentro del espacio. De esta manera, la variabilidad estilística tiene una función 
de delimitación, que refuerza las diferencias sociales y define territorios de una manera visual.

Pese a la gran dificultad de obtener información sobre la densidad de las poblaciones en el pasado y, en algunos casos, sobre las condiciones paleoambientales, algunos estudios han demostrado que esta teoría puede explicar que la variabilidad estilística en el arte rupestre de sociedades cazadoras-recolectoras tiene relación con los procesos sociales ocurridos dentro de ellas (McDonald 2000). Así, el análisis de elementos vinculados con el estilo en el arte rupestre abre la posibilidad de acercarnos a aspectos ideológicos, simbólicos y de interacción, comprendiendo que cualquier representación visual implica elementos que se comparten en códigos de representación y significación, los que son aprehendidos y utilizados por el individuo o grupo que realiza el arte rupestre. En otras palabras, los diseños y sus combinaciones tienen un carácter comunicativo que implica tanto la transmisión de información social como la identidad grupal e individual (Wiessner 1983).

Los motivos y las técnicas empleadas en el arte rupestre pueden transmitir un sentido de identidad y pertenencia a un grupo $y$, por lo tanto, un diseño puede desempeñar roles tanto dentro como fuera de la sociedad que lo produce. Así, las diferencias en los motivos que identifican a grupos vecinos se pueden observar, reconocer y utilizar como estrategias de interacción social y de demarcación del espacio geográfico.

De esta forma, la teoría del intercambio de información se relaciona con la identidad social, entendida como proceso colectivo, lo que nos permite utilizarla para interpretar prácticas relacionadas con la identidad social de los habitantes del Ibáñez medio en el pasado.

\section{El arte rupestre en el río Ibáñez medio}

Como hemos mencionado en párrafos anteriores, los estudios de arte rupestre en el Ibáñez medio generalmente han sido abordados desde los grupos estilísticos previamente propuestos para la Patagonia central (Gradin et al. 1979, Gradin 1983, Gradin \& Aguerre 1994).

En cuanto al presente registro, este se realizó a partir del establecimiento de una serie de variables que fueron divididas en dos grandes componentes: el primero asociado al sitio arqueológico en sí, y el segundo relacionado con las representaciones que fueron plasmadas en estos. Esto dio como resultado un total de 1035 motivos en los 29 sitios relevados sistemáticamente (Muñoz \&
Artigas 2016), de los cuales 321 corresponden a manchas indeterminadas. Entre los 714 motivos restantes existe un marcado predominio de las improntas de manos. En menor número se registraron motivos geométricos como puntos, líneas, grecas y negativos de placa, como también zoomorfos, siendo estos últimos únicamente representados en tres sitios: RI-04, RI-24 y RI-58 (fig. 2).

Con respecto a las improntas de manos, la técnica del negativo es la más utilizada, mientras que no se aprecia una diferencia notoria con respecto a la lateralidad al agrupar tanto los positivos como los negativos, aunque existe una leve preponderancia de manos derechas $(n=205)$ sobre las izquierdas $(n=191)$. Es de especial relevancia recalcar que en buena parte de la muestra no se pudo determinar la lateralidad, lo que arrojó un número total de 288 improntas de mano indeterminadas. Esta homogeneidad desaparece cuando observamos las lateralidades según las técnicas (Artigas \& Muñoz 2015, Muñoz \& Artigas 2016) (fig. 3).

En la primera fila de la figura 3 se muestra la totalidad de manos; en la segunda, la proporción de izquierdas, derechas y no determinadas en los negativos; en la tercera, los positivos y la preferencia de manos derechas.

Un elemento que llamó la atención es la presencia de lo que denominamos "manos pequeñas" registradas en 11 sitios. Con relación a la muestra total, los motivos de manos pequeñas corresponden solo a un $12 \%$, predominando las manos grandes (88\%). Sin embargo, al analizar la técnica utilizada se aprecia un porcentaje mayor de positivos en las manos pequeñas (14\%) en comparación con las manos grandes, donde los positivos apenas alcanzan el 4,6\% (fig. 4).

En los motivos zoomorfos la única especie reconocida y representada es el guanaco, en su mayoría con vientre abultado, destacando la presencia de una "guanaca con cría" en RI-04 y dos conjuntos de zoomorfos en RI-58 Y RI-24 (fig. 5). En este caso es posible reconocer que las figuras fueron realizadas con líneas muy finas, lo que implica el uso de algún tipo de herramienta en su fabricación. Los diseños son particularmente escasos y siempre se encuentran aislados de otro tipo de motivos.

Los motivos geométricos representan un grupo pequeño $(1,5 \%)$, encontrándose la mayoría de ellos en un solo sitio (RI-22). La técnica más común es la aplicación de pinturas con los dedos. Dentro del grupo de "geométricos", incluimos las figuras rectangulares manufacturadas por sopleteado que representan el 0,4\% (fig. 6) y se registran solo en dos sitios (RI-01 y RI-11). 


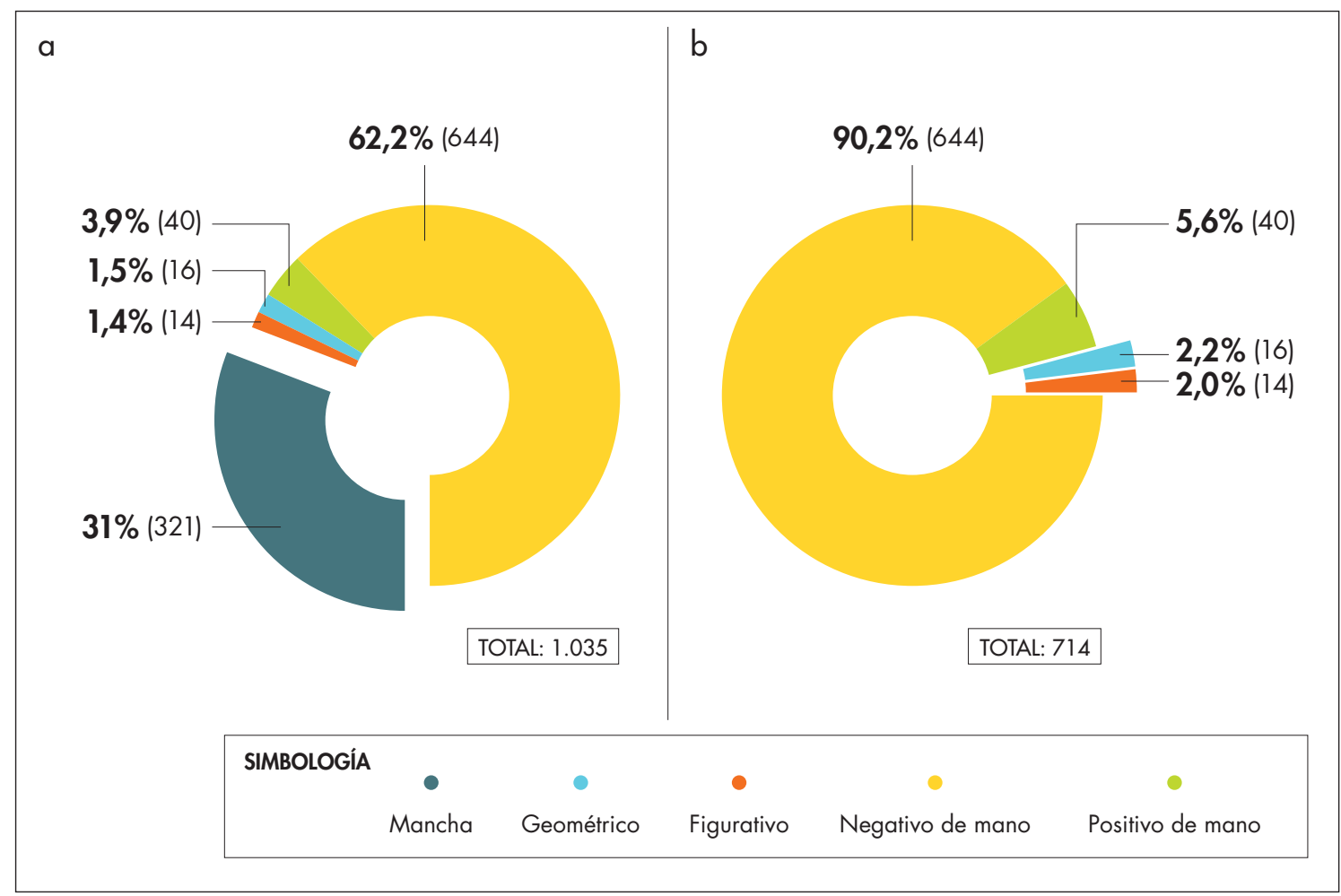

Figura 2. Gráfico en el que se muestra el porcentaje de diseños: a) en relación con los 1035 motivos, considerando las manchas de color; b) considerando los 714 motivos figurativos y abstractos. Figure 2. Graph showing the percentages of designs: a) for all 1035 motifs, including color splotches; $\boldsymbol{b}$ ) including only the 714 figurative and abstract motifs. (Dark grey=splotches; light grey=geometric; hatched=figurative; yellow=relief hand print; ivory=hand print.)

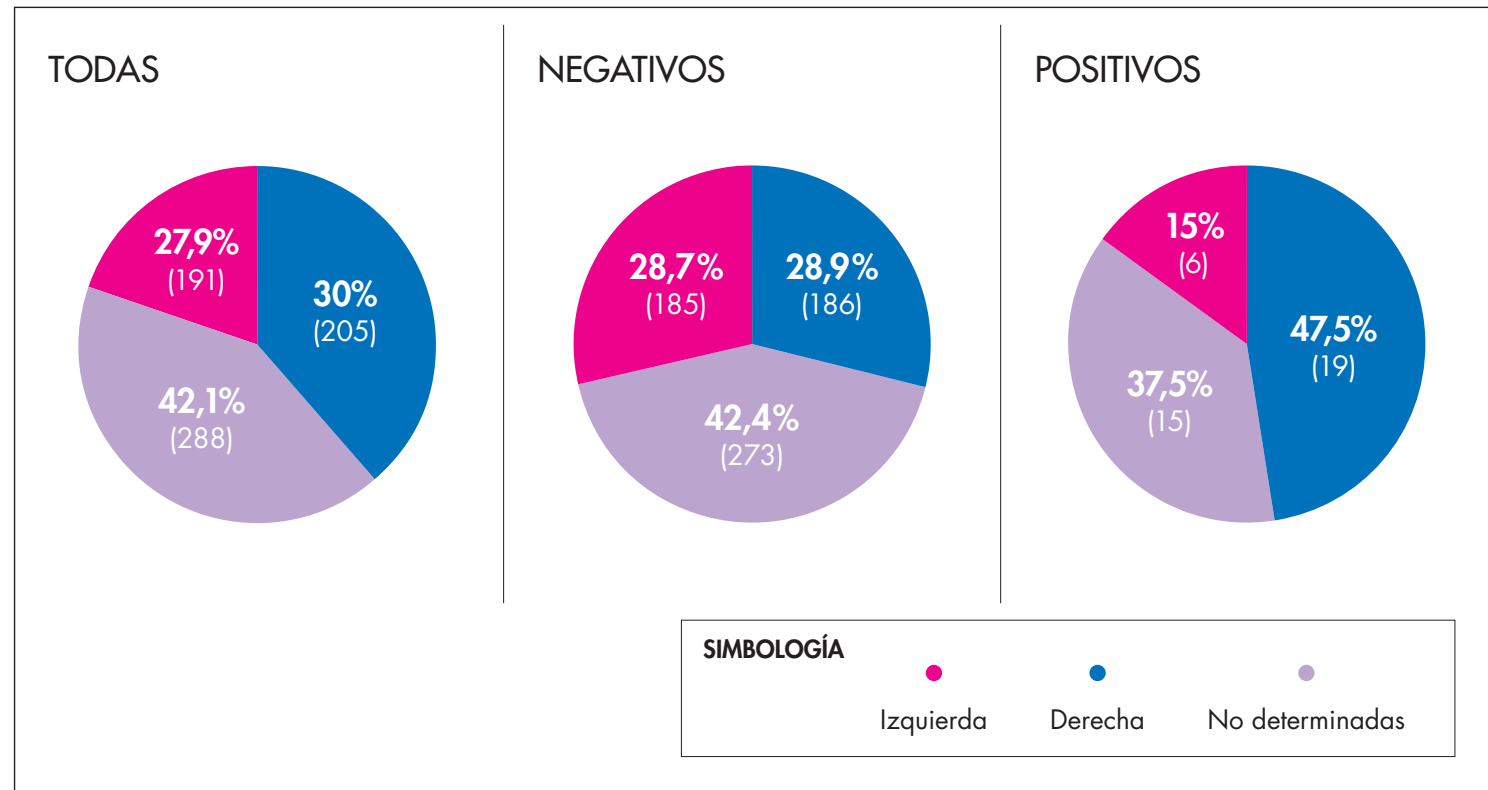

Figura 3. Porcentaje de lateralidad en las improntas de manos. Figure 3. Percentages of right versus left hand prints. 

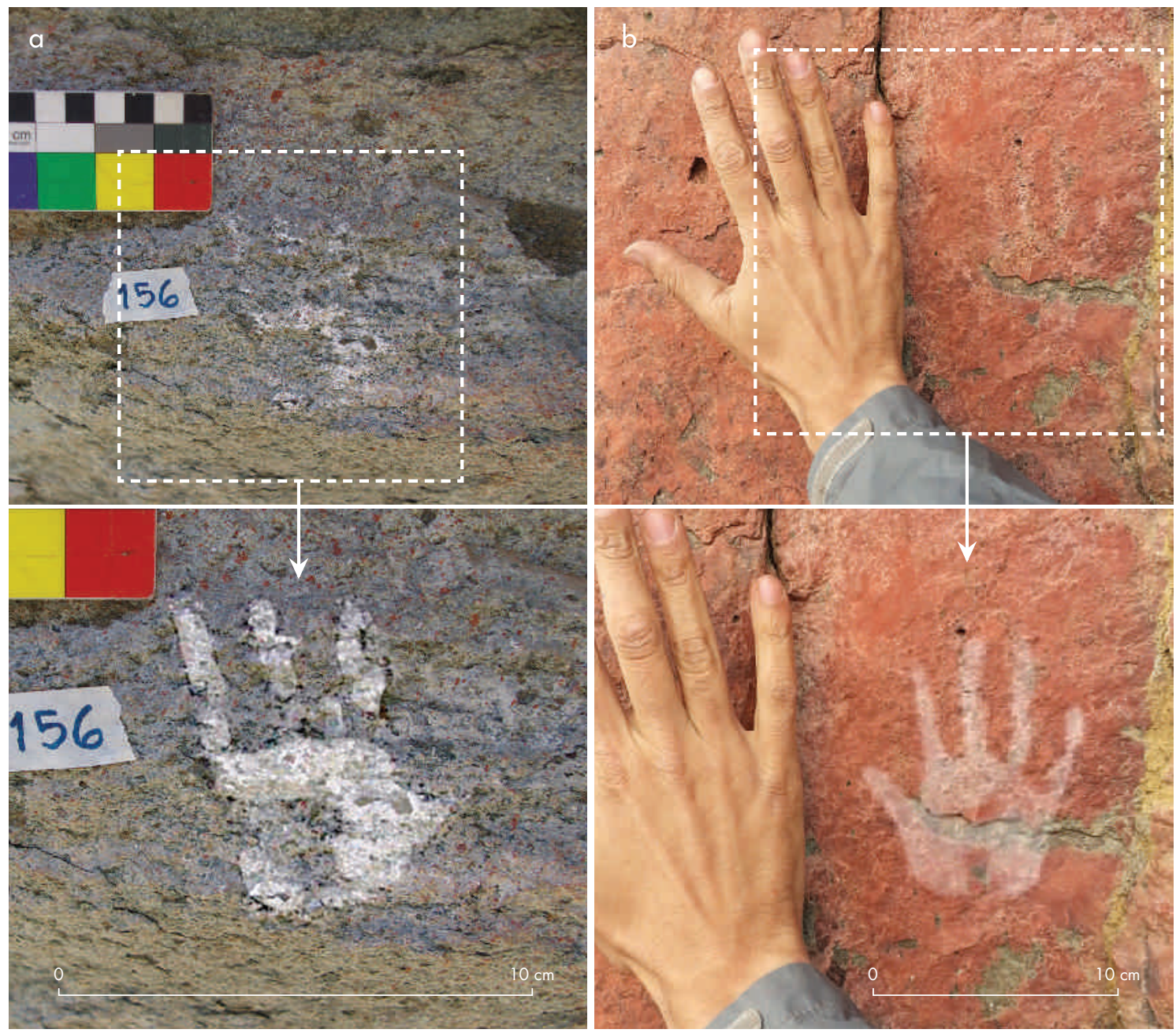

Figura 4. Registro de manos pequeñas (imágenes retocadas digitalmente). Figure 4. Small hand prints (digitally rotouched images).

Respecto de la coloración, predomina el color rojo ( $\mathrm{n}=664)$. Además, se encontraron 13 diseños de color amarillo, 32 de color blanco y 5 de color verde. En cuanto a las superposiciones halladas en 9 sitios, suelen estar presentes en aquellos lugares con mayor número de motivos, aunque generalmente son poco abundantes en el área.

Otro aspecto relevante es la conformación de los motivos en los sitios. En el caso de los motivos de guanaco, estos suelen representarse todos juntos en un determinado espacio de los soportes rocosos, mientras que las improntas de manos se extienden a lo largo del soporte.

\section{Particularidades en la elaboración y conformación del arte rupestre de la zona}

En cuanto a las improntas de manos, tal como se ha mencionado, la técnica preferida es el negativo. Sin embargo, esto cambia al analizar las manos pequeñas, pues muchas veces resulta más fácil marcar la mano de un niño estampándola que estarciéndola. Esto parece corroborarse con la idea de que las manos más pequeñas que hemos registrado son positivos.

En cuanto a la manufactura del arte rupestre en el Ibáñez medio, sabemos que esta va de la mano con la aplicación de pigmentos y técnicas de diseño (Fiore 


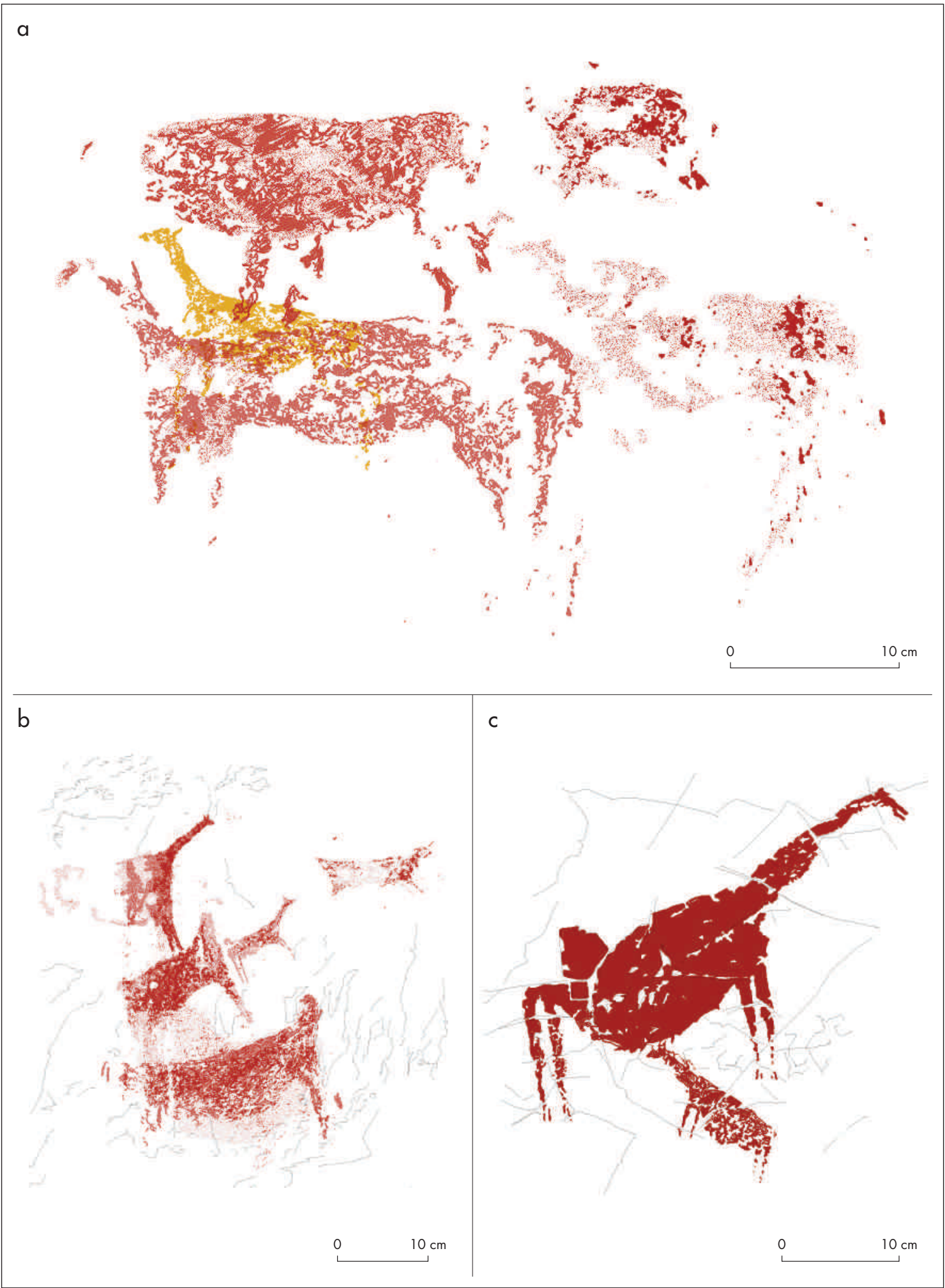

Figura 5. Motivos zoomorfos registrados en RI-24, RI-58 y RI-04. Figure 5. Zoomorphic motifs recorded at RI-24, RI-58, and RI-04. 

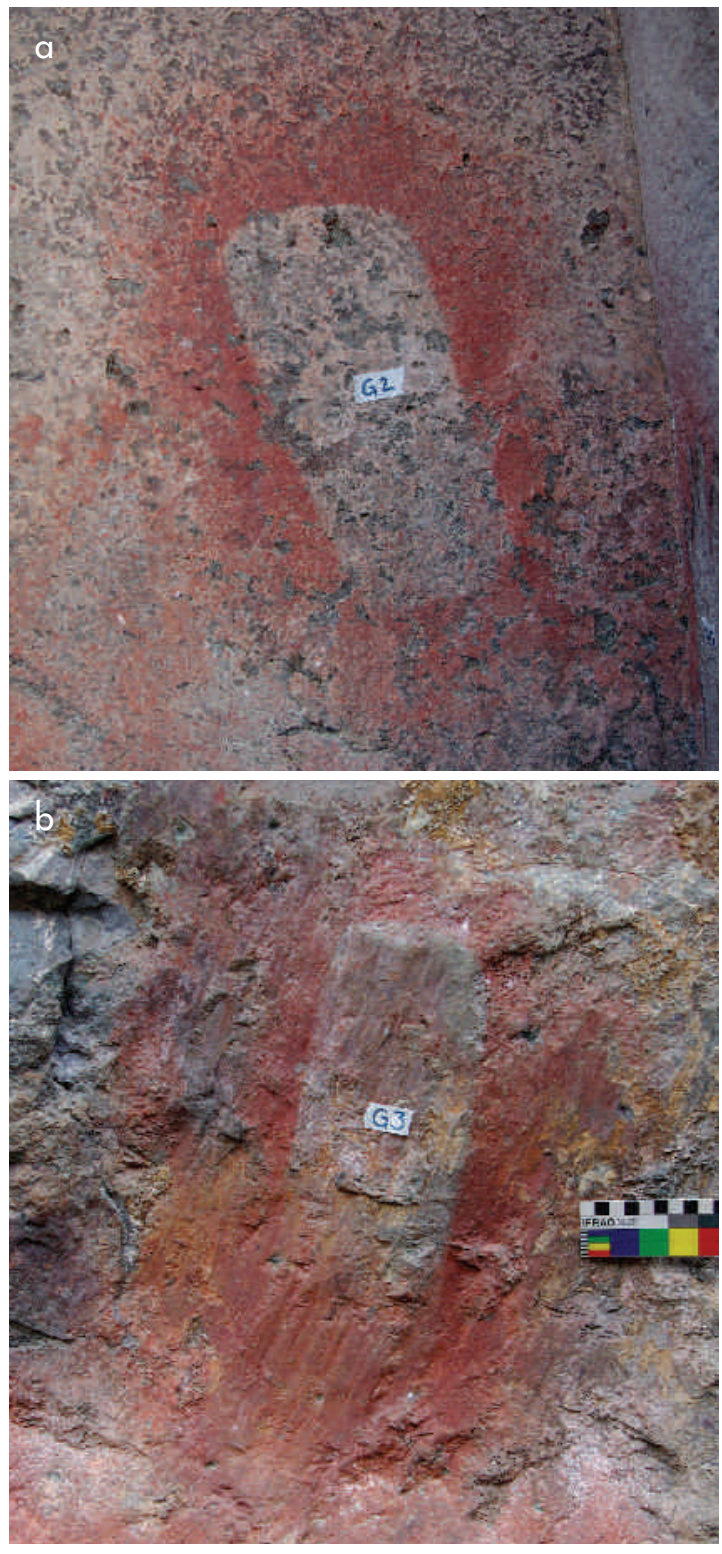

Figura 6. Motivo geométrico rectangular o "placas", ubicado en los sitios RI-01 y RI-11. Figure 6. Rectangular geometric motifs or "plates" identified at sites RI-01 and RI-11.

2009), es decir, con las herramientas utilizadas (pinceles, dedos, hisopos, etc.), y las opciones en cuanto a la forma y configuración para hacer las figuras. De acuerdo con Troncoso (2003), cualquier intento de comprender cómo se hizo el arte rupestre se basa en el supuesto de una norma en el estilo que puede expresarse en diferentes niveles: técnico, iconográfico y espacial. Por lo tanto, los
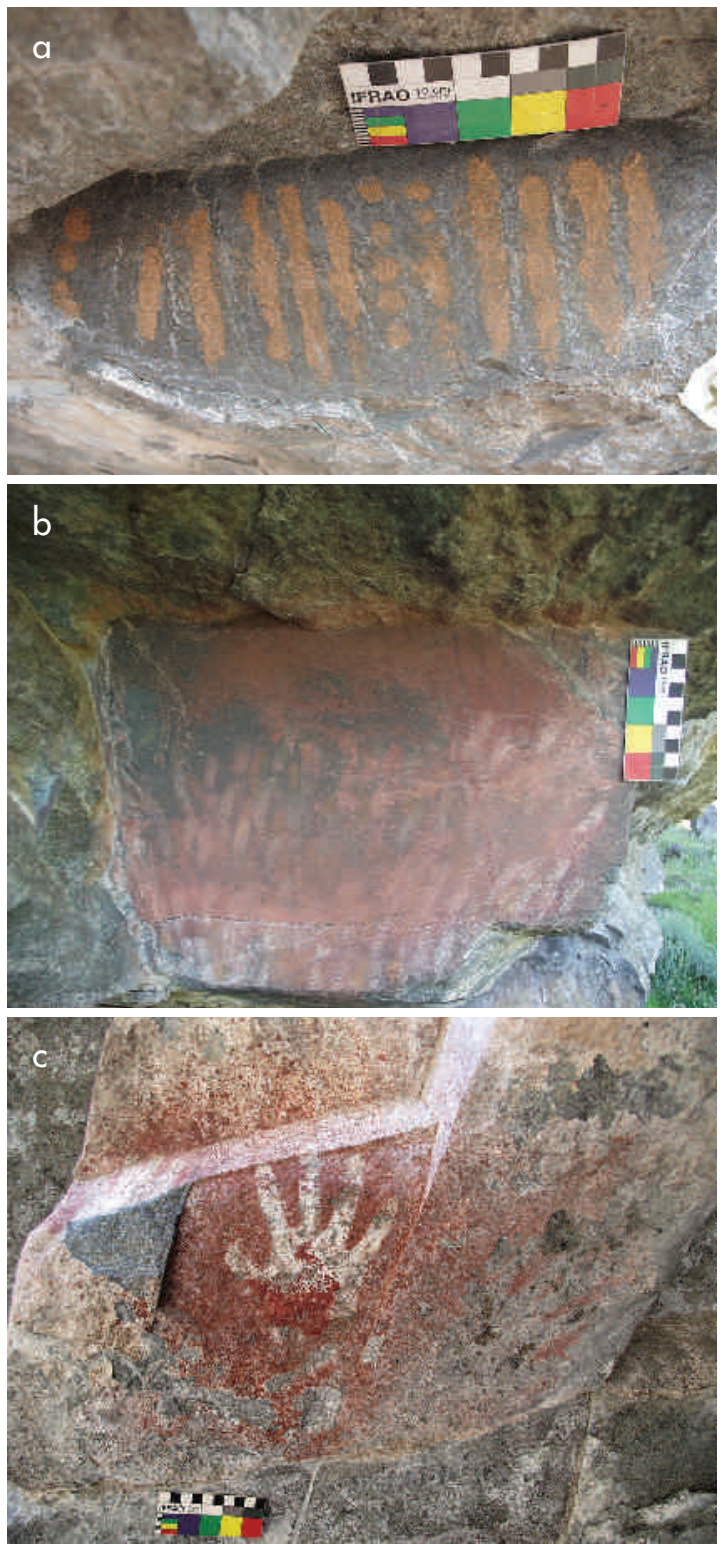

Figura 7. Motivos de líneas, puntos y manos manufacturados sin herramientas (a y b corresponden al sitio RI-22; C corresponde al sitio RI-01). Figure 7. Linear, spotted, and hand motifs created without tools ( $a$ and $b$ correspond to site RI-22; C corresponds to site RI-01).

atributos compartidos en la manufactura, asociados con un estilo tecnológico, están conectados con las nociones de relaciones sociales más estrechas entre los artistas.

En este sentido, el arte rupestre del Ibáñez medio demuestra la existencia de sistemas constructivos similares, especialmente en lo que se refiere a la técnica de elaboración de improntas en negativo mediante el 

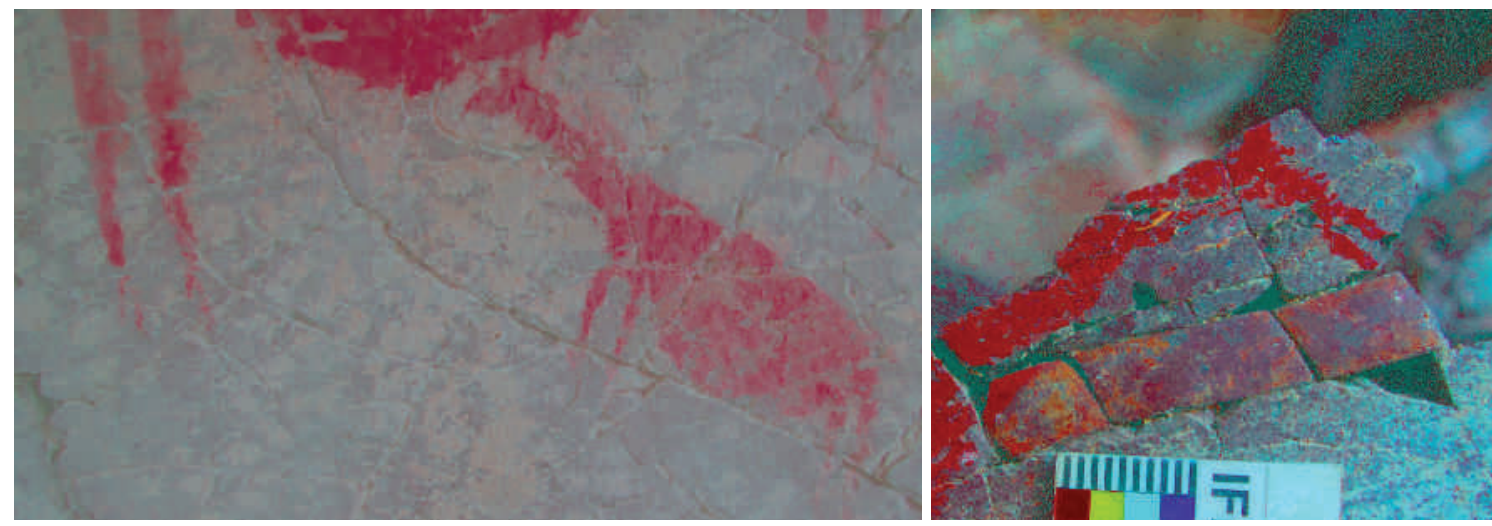

Figura 8. Terminación de los trazos correspondientes a las patas de un motivo zoomorfo del sitio RI-04. Figure 8. Close-up of the extremities of a zoomorphic motif's legs at site RI-04.

sopleteado, además del uso de los dedos como pincel (sin necesidad de herramientas), como es el caso de algunos de los diseños geométricos registrados en el área (fig. 7).

Sin embargo, y a pesar de estas similitudes, hay representaciones que revelan una manufactura diferente, como las figuras de guanacos y algunos motivos geométricos, elaborados posiblemente a partir del uso de herramientas como pinceles o hisopos, lo que se ha observado a través del análisis de los trazos en algunas pinturas (fig. 8). En estos casos también es relevante considerar ciertos negativos de mano que pudieron haber sido hechos mediante "untado": diferencias generales podrían indicar estilos distintivos.

\section{Memoria, estilo e intercambio de información}

Considerando la existencia de grupos vecinos en las áreas sociales que se logran evidenciar mediante las distribuciones de diseños y materiales distintivos, puede especularse que la baja presencia de motivos zoomorfos y geométricos, en comparación con los motivos de manos, podría reflejar la entrada de sistemas de información visual desiguales. De esta manera, es posible vislumbrar grupos que marcaron el espacio de una manera distinta, abriendo las redes sociales en determinados momentos e integrando en su mismo espacio sistemas de comunicación diferenciados.

Las conexiones estilísticas observadas en el Ibáñez medio podrían estar relacionadas con conocimientos tradicionales, en el supuesto de que son susceptibles de ser reproducidos de manera inconsciente en las prácti- cas artísticas y como códigos compartidos. Del mismo modo, la existencia de configuraciones morfológicas y la disposición de los espacios comunes en el área se relacionan con los contextos que podrían estar operando bajo la misma lógica comunicacional, inherentes a las modalidades estéticas repetitivas.

La uniformidad estilística manifestada en el Ibáñez medio podría ser representativa de una zona de mayor densidad comunicativa (Wobst 1977) dentro de un contexto simbólico de comunicación. Esto se debe a que los lugares en los que se encuentra el arte rupestre operarían como espacios simbólicos para los grupos que lo produjeron (Criado 1993, Thomas 1995, Troncoso 1998).

Con el fin de evaluar con precisión cómo la interacción, el intercambio de información y las influencias culturales entre grupos sociales se reflejan en el arte rupestre, nuestro análisis ha considerado esta materialidad como un sistema en conjunción, con presencia de distintos patrones estilísticos. Esto pone de relieve la importancia del intercambio como un medio de transferir los aspectos intangibles de la cultura, así como los aspectos técnicos de la producción rupestre y los estilos.

Estas dinámicas y características comunes en los sitios de arte rupestre hablarían de relaciones estilísticas compartidas en toda el área que podrían traspasar diferentes períodos temporales. Desafortunadamente no hay suficiente información cronológica en la zona para confirmar o negarlo. Los datos que brinda la presencia de algunos casos de superposición son bastante limitados y no es posible realizar una cronología basada en la superposición; sin considerar que la misma solo 


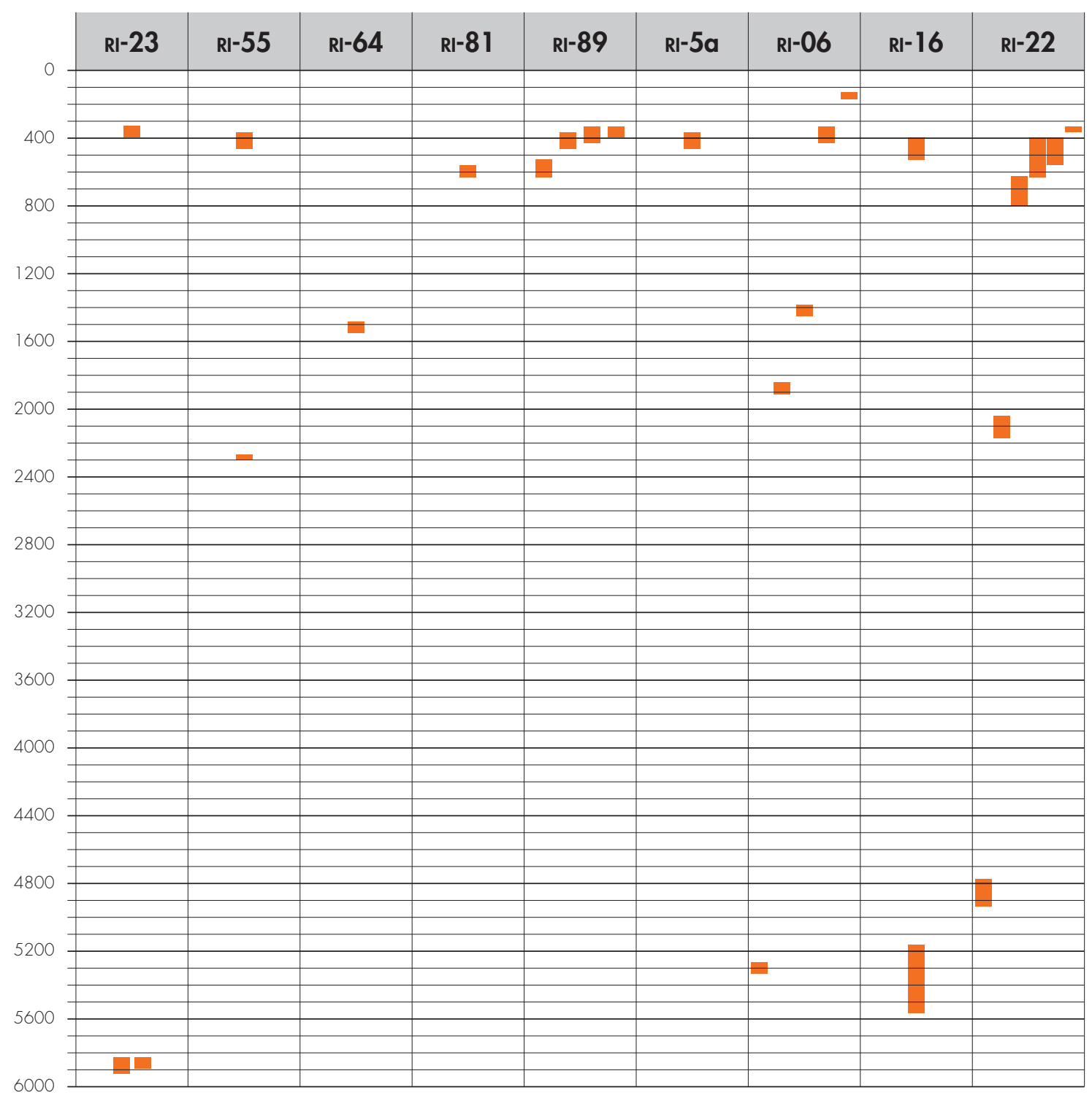

Figura 9. Fechados obtenidos en las investigaciones realizadas previamente en el sector del Ibáñez medio (Mena 1983, 1992; Velásquez \& Trejo 2003; Mena et al. 2013). Figure 9. Dates obtained in previous studies of the Middle Ibáñez sector (Mena 1983, 1992; Velásquez \& Trejo 2003; Mena et al. 2013).

entrega una cronología relativa con la imposibilidad de reconocer tiempos o lapsos de tiempo específicos.

Por lo anterior, y basándonos en la premisa de que el sector del Ibáñez medio fue ocupado por distintos grupos aproximadamente entre el $6000 \mathrm{AP}$ hasta el 300-200 AP, es posible plantear que estos podrían haber generado un mismo sistema simbólico expresado a través de la permanencia de un mismo motivo, como lo son las improntas de manos. Esto explicaría -a partir de la integración que hace Armstrong (2012) del trabajo de Halbwachs (1968) a los estudios de arte rupestre- la idea de una memoria colectiva, entendida como una construcción social en que la memoria del pasado interactúa con la del presente (Halbwachs 1968), manteniendo así ciertos códigos plasmados en los motivos expresados en el Ibáñez medio. Esto se sustenta en las distintas ocupaciones descritas a partir de las excavaciones realizadas en el sector (fig. 9). 
Los distintos momentos ocupacionales presentes en los sitios con arte rupestre suelen estar separados tanto por depósitos de ceniza del volcán Hudson, como por matrices compuestas por bloques rocosos producto del desprendimiento o derrumbe del techo y paredes de los aleros y cuevas (Mena \& Buratovic 1997). Esto ha llevado a postular que las ocupaciones en el Ibáñez podrían estar sujetas a periodos de abandono, existiendo hiatos en la secuencia temporal (Mena \& Ocampo 1993).

A partir de lo anterior, es posible enunciar que la ocupación del Ibáñez medio evidencia la presencia de distintos grupos de cazadores-recolectores que habitaron el espacio en momentos cronológicos diferentes. Sin embargo, dichos grupos conservan una memoria colectiva basada en conocimientos pasados unidos a una memoria del presente reconocible, como hemos dicho antes, en el mantenimiento de ciertos motivos como las improntas de manos. Sabemos que para afirmar fehacientemente esto es necesario contar con una batería de dataciones de las pinturas para definir con seguridad el lapso de tiempo en que fueron manufacturadas. Lamentablemente, las pinturas que se ha intentado fechar han entregado resultados infructuosos (Steelman 2014).

\section{Espacios con arte rupestre en el río Ibáñez medio y su visibilidad}

Considerando a Criado (1993) y el concepto de monumento asociado al arte rupestre, el paisaje se convierte en un importante escenario para la acción humana y un elemento clave en el estudio arqueológico de las sociedades (Troncoso 1998). A través de las diferentes categorías analizadas en nuestro trabajo, creemos que hubo una opción (voluntaria) en la elección de los espacios donde se plasmaron las pinturas. Por ejemplo, hay una clara preferencia de sitios que se orientan hacia el norte (58,6\% de los yacimientos), porcentaje que sube a un $72,4 \%$ si consideramos los sitios que miran al noreste.

En cuanto a la distribución del arte rupestre, se ha observado la existencia de algunos patrones espaciales dentro del paisaje, en concreto la posición de todos los sitios en la orilla sur del río Ibáñez (fig. 11). Esto podría estar relacionado, entre otras cosas, con la geografía de la zona y la relación de las pinturas con la luz del sol, ya que tal distribución permite la exposición directa a más horas de luz al día, teniendo en cuenta que la temperatura media anual en la zona es de $10^{\circ} \mathrm{C}$.
Fundamentados en los elementos señalados anteriormente, la ubicación de los sitios con arte rupestre podría sugerir que este tipo de manifestación cultural se encuentra en algunos lugares considerados adecuados para contener este tipo de representaciones, es decir, en zonas con características geográficas específicas (Bradley et al. 1995, Troncoso 1998), en asociación constante con los recursos hídricos y con una altura promedio entre 550 y 700 msnm (52\% de sitios con arte rupestre). En este contexto, las pinturas representadas en los sitios no son de ninguna manera aleatorias, puesto que hemos identificado espacios con paredes rocosas que podrían considerarse adecuadas para ser pintadas pero que no poseen ningún tipo de manifestación gráfica.

Según Hernando (2002), en sociedades cazadorasrecolectoras la percepción de la realidad se determina a través del mito, los fenómenos naturales y el eje espacial. A partir de esto y en el contexto de una memoria colectiva construida en el ethos de grupos cazadoresrecolectores (Armstrong 2012), es probable que las poblaciones del área de estudio tuviesen una estrategia visual relacionada con el espacio y la movilidad de los grupos, donde los sujetos se apropiaron de la memoria a través del movimiento que se realiza en un entorno familiar y culturalmente aprehendido. Por lo tanto, la memoria se reproduce en el ambiente doméstico en relación con otras actividades diarias. En este sentido, el arte rupestre puede haber funcionado como un elemento de demarcación del tiempo en un espacio constantemente ocupado.

Tal reocupación se refleja en la datación de algunos de los sitios excavados, que cubren un rango cronológico desde 5800 a 350 años AP (RI-23, RI-06, RI-22). Esta es una evidencia de la presencia constante de grupos cazadores-recolectores que utilizan los mismos espacios, donde parece no importar en qué época se hicieron (o no) los diseños rupestres, el espacio se usa igual y con lógicas similares.

Otro elemento interesante identificado es el bajo nivel de superposición presente en los sitios. Esta configuración no debe entenderse como algo casual, sino como el resultado de varios procesos socioculturales en que los individuos y los grupos que produjeron el arte rupestre se relacionaron con las manifestaciones anteriores de una manera particular (Armstrong 2012, Martel et al. 2012). En este sentido, es posible interpretar este hecho como un tipo relación de las poblaciones con el pasado, es decir, a través de un modo que podría 
simbolizar un acto de respeto hacia las pinturas plasmadas previamente en las paredes, fenómeno que se ha interpretado para otras zonas de Chile y Argentina (Armstrong 2012, Martel et al. 2012).

Podemos comparar esta interpretación con la observación de los estudios etnoarqueológicos de áreas distantes, donde la práctica de pintar manos aún se mantiene, como en Arnhem Land (Australia). Allí, la sobreposición de diseños se considera un homenaje, ya que al pintar y repintar se renuevan los vínculos con los espíritus y los antepasados (Taçon 1989, Taçon 1994, Taçon \& Chippindale 1998, Domingo-Sanz \& May 2008, May 2009). El no sobreponer los diseños en nuestra área de estudio podría responder a otra lógica de presentación, pero también haría hincapié en los usos y reúsos de los espacios, ya que parece poco probable que los sitios con gran cantidad de manos se hayan pintado de una sola vez. Es posible que la constante necesidad de volver a repintar en paredes responda a una práctica que apunta a actitudes similares, aunque en momentos distintos. Creemos, pues, que la comprensión de que este fenómeno de "volver" y "repintar" forma parte integral de la obligación de los grupos para cuidar su territorio y revivir el significado cultural y sus tradiciones ancestrales (Taçon 1989, Taçon 1994, Taçon \& Chippindale 1998, Domingo-Sanz \& May 2008, May 2009).

\section{Función y posibles significados de los motivos de improntas de manos}

$\mathrm{Al}$ entender el arte rupestre (y la cultura material en general) como un fenómeno social significativo, se puede interpretar como un medio de comunicación social y un medio simbólico que guía a las personas en su entorno social y natural (Shanks \& Tilley 1987). En cuanto medio de comunicación, el arte rupestre se puede manipular sobre la base de una variedad de estrategias y prácticas relacionadas con los intereses e ideologías sociales.

En el área de estudio, el rango más limitado de motivos implica que se requiere un menor grado de variabilidad artística para la delimitación territorial en comparación con otros valles de la Patagonia central. A la luz de esto, pareciera que la amplia presencia de los motivos de mano podría cumplir la función de fomentar la cohesión social entre los grupos (fig. 10).

En este sentido, los estudios realizados por Casimir (1992a, 1992b) sugieren que existe una tendencia entre los grupos móviles para definir los derechos de propiedad en los lugares donde los recursos están en competencia. Al mismo tiempo, Ingold (1987) ha propuesto que el arte rupestre constituye un sistema de mensajes relativos a las particularidades de los lugares donde se ubica. Dichos mensajes servirían para ser leídos por grupos extranjeros. Esto concuerda con la descripción de Greer \& Greer (1999), quienes han interpretado los motivos de manos en el área de Smith River (Montana Central, Estados Unidos) para definir y establecer ciertas asociaciones dentro de los grupos culturales y su funcionamiento como elementos que transmiten información de rutas, zonas de caza, o identidades tribales.

En otro sentido, Clegg (1995) sugiere que las manos son formas de auto-expresión y de representación mimética, puesto que dichas improntas formarían parte de un proceso de transmisión de información sobre un evento en un espacio y tiempo determinados, dejando una réplica de uno mismo (Dobrez 2013). De acuerdo con Dobrez (2013), las manos expresarían un acto particular y funcionarían como testimonio de una identidad humana; por lo tanto, la representación de la misma se convierte en un anuncio personal. Esto se suma a los significados simbólicos que distintos filósofos y psicólogos han dado a la "mano": símbolo arquetípico de la expresión del estado interior del ser humano a partir del gesto, o bien, por sus cinco dedos, como representación identitaria del ser humano con sus cinco extremidades (dos piernas, dos brazos y una cabeza) (Cirlot 2005).

En Australia los motivos de manos han sido asociados con significados culturales y están íntimamente ligados a la identidad del fabricante, relacionado con la idea de una "firma", en el sentido de la identidad-autor, es decir, como la marca de una persona que pudo haber establecido asociaciones especiales con un área particular (Dobrez 2013). Asimismo, en las comunidades aborígenes australianas los motivos de manos se han utilizado como parte del concepto de living memory (Layton 1992, Mulvaney 1996).

Otros estudios (Moore 1977: 322) han propuesto siete categorías con respecto a cómo se han utilizado los motivos de manos por los grupos aborígenes australianos: a) firma individual de un artista o demarcación de una visita; b) memorial; c) mensaje a los espíritus de los antepasados; d) comunicación secular con los demás; e) registro de acontecimientos históricos; f) inscripción sagrada del mito; g) medios para el uso o la invocación del poder mágico-religioso. Así entendido, los motivos 

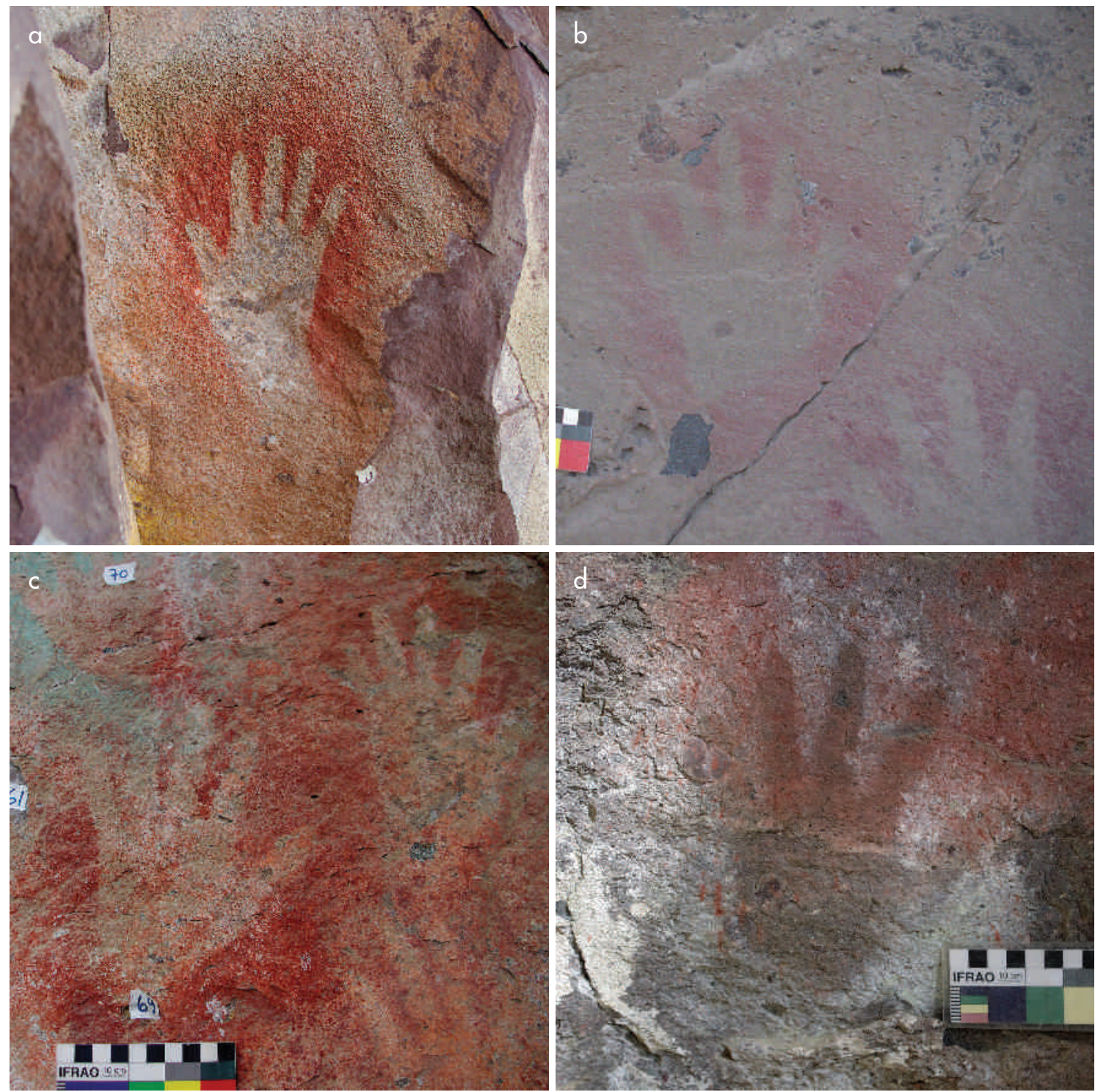

Figura 10. Ejemplos de motivos de manos en negativo registrados en los sitios: a) RI-91; b) RI-03; c) RI-01; d) RI-28. Figure 10. Examples of relief hand prints recorded at sites: $\boldsymbol{a}){ }_{R I}-91 ; \boldsymbol{b}$ ) RI-03; c) RI-01; d) RI-28.

de manos permiten la conservación de las ideas y principios particulares, que pueden estar relacionados con la necesidad de las sociedades cazadoras-recolectoras de realizar y externalizar determinados contenidos de la memoria individual y colectiva (Halbwachs 1968, Armstrong 2012).

Ambos motivos de manos, en negativo y positivo, pueden entenderse como elementos de autorreconocimiento de la persona en relación con el medio ambiente, dejando claro que existe una conciencia del efecto que esto tiene en el mundo. El hecho de que tales marcas permanezcan en el tiempo proporciona un estatus especial a los actos de los individuos, lo que deriva en un registro visual legible de la vida y del medio ambiente de sus creadores (Dobrez 2013).

A través de la disposición de los motivos, en este caso las manos, el espacio comienza a adquirir un significado particular, convirtiéndose en un medio que introduce el ser y la cultura en el espacio y la naturaleza. Esto produce un efecto doble: en primer lugar, el de 
"naturalizar" algunos conceptos gráficos y, en segundo lugar, de "culturizar" la naturaleza. Troncoso (1998) plantea que es probable que esta acción de expresar conceptos culturales en el espacio tenga una importante función ideológica a través de símbolos de arraigo en la naturaleza, que adquieren una permanencia cronológica y con ello un importante potencial, puesto que implica una concepción del tiempo que se extiende más allá del diario vivir (Criado 1991, Bradley 1993).

Es difícil hacer una distinción clara entre las manos que podrían ser de hombres o de mujeres adultas (Gunn 2006), y la existencia de esta clase de motivos con proporciones claramente pequeñas (cerca de un $12 \%$ de las manos registradas) nos permite suponer la existencia de niños. Es posible que las comunidades que utilizaron este espacio lo hicieran bajo condiciones particulares, movilizándose por el valle acompañadas de niños pequeños, lo que sugiere una manera de utilizar el paisaje como un espacio familiar con la participación de los niños en la producción del arte rupestre. Así, esta manifestación se convierte en una clave para entender las sociedades que habitaron el área en el pasado.

\section{CONSIDERACIONES FINALES}

La comparación detallada de estilos específicos, motivos y técnicas utilizadas en el arte rupestre del Ibáñez medio, permite concluir que, a pesar de que existen algunas similitudes con otras áreas de la Patagonia central, nuestra área de estudio contiene una gama más limitada de motivos y técnicas que otros valles circundantes.

La teoría del intercambio de información hace hincapié en la idea de que la diversidad estilística se desarrolla de acuerdo con la disponibilidad de recursos, la densidad de población y la necesidad de los grupos para facilitar la interacción social o delimitar los territorios. En nuestro estudio hemos observado que existe un alto grado de homogeneidad estilística que podría indicar algún tipo de delimitación territorial. Dicha delimitación funcionaba como mecanismo promotor de la cohesión social entre los grupos. En este sentido, se ha hablado de la existencia de variaciones regionales menores que indican la presencia de grupos culturalmente diferenciados, lo que sugiere la posible apertura de las redes sociales por períodos determinados de tiempo. Los diseños que se escapan del patrón homogéneo del área, como los guanacos o los motivos geométricos, podrían plantearnos nuevas posibilidades. Por ejemplo, patrones de movimientos más amplios que comunicarían las pampas con los bosques, generando nodos de interacción, evidenciándose una interrelación entre momentos asociados a sistemas más cerrados y otros a periodos de apertura. Dicha hipótesis deberá ser contrastada a la luz de los nuevos antecedentes que futuras investigaciones puedan arrojar en la región.

Agradecimientos a la gente de Cerro Castillo que nos permitió acceder a los sitios y nos ayudó de muchas maneras, especialmente a don Niba, Sandra, Pancho Malo, Tati, la señora Inés y su marido. No podemos olvidar al equipo que participó en el Fondecyt 1110556 a cargo de Francisco Mena. Muchas gracias, Pancho, por dejarnos hacer este trabajo, y a todos quienes nos ayudaron en el registro de los sitios: Víctor Lucero, Renata Gutiérrez, Iván Maureira y María Luisa Gómez.

\section{NOTAS}

${ }^{1}$ En un primer momento se identificaron tres niveles culturales, sin embargo, Fuentes \& Mena (2010) descartan el nivel más antiguo por un componente únicamente paleontológico sin evidencias antrópicas.

\section{REFERENCIAS}

Armstrong, F. 2012. Engraved memory: petroglyphs and collective memory at Los Mellizos, Illapel, Chile. Rock Art Research: the Journal of the Australian Rock Art Research Association (AURA) 29 (1): 19-34.

Artigas, D. \& MuÑoz, C. 2015. Arte rupestre en el curso medio del río Ibáñez: retomando el camino de la interacción de las manifestaciones artísticas al contexto regional. En Actas del XIX Congreso Nacional de Arqueología Chilena, pp. 507-514. Arica.

Aschero, C. 1996. ¿A dónde van esos guanacos? En Arqueología. Solo Patagonia. Ponencias de las II Jornadas de Arqueología de la Patagonia. O. Gómez, Ed., pp. 153-162. Puerto Madryn: CenPat-Conicet.

Aschero, C. 2012. Las escenas de caza en Cueva de las Manos: una perspectiva regional (Santa Cruz, Argentina). En L'art pléistocène dans le monde, J. Clottes, Ed., pp. 807-823. Tarascon-sur-Ariège: Société Préhistorique Ariège-Pyrénées.

BAtE, F. 1970. Primeras investigaciones sobre el arte rupestre de la Patagonia chilena. Anales del Instituto de la Patagonia 1: 15-25.

BAte, F. 1971. Primeras investigaciones sobre el arte rupestre de la Patagonia chilena (segundo informe). Anales del Instituto de la Patagonia 2: 33-41. 
Berquist, N., Bustos, V. \& Sandoval, N. 1983. Ms. Investigaciones arqueológicas en la comuna de río Ibáñez - XI Región, Informe final, División de asistencia técnica, Ciudad Universitaria, Concepción.

Bird, J. 1993. Viajes y arqueología en Chile Austral. Punta Arenas: Ediciones Universidad de Magallanes.

Borrero, L. 1989-1990. Evolución cultural divergente en la Patagonia austral. Anales del Instituto de la Patagonia 19: $133-140$

Boschín, M. 1994. Arte rupestre patagónico: problemas no resueltos y propuestas para su discusión. Anuario del IEHS 9: 232-354.

BRADLEY, R. 1993. Altering the earth: the origins of monuments in Britain and continental Europe. Edimburgo: Society of Antiquaries of Scotland.

Bradley, R., Criado, F. \& Fábregas, R. 1995. Rock art and the prehistoric landscape of Galicia: the results of filed survey 1992-1994. Proceedings of The Prehistoric Society 61: $347-370$.

CARDEN, N. 2009. Imágenes a través del tiempo. Arte rupestre y construcción social del paisaje en la Meseta Central de Santa Cruz. Buenos Aires: Sociedad Argentina de Antropología.

CAsimir, M. 1992a. The dimensions of territoriality: an introduction. En Mobility and territoriality, M. Casimir \& A. Rao, Eds., pp. 1-26. Oxford: Berg Publishers.

Casimir, M. 1992b. The determinants of rights to pasture: territorial organization and ecological constraint. En Mobility and territoriality, M. Casimir \& A. Rao, Eds., pp. 153-203. Oxford: Berg Publishers.

Cirlot, J. 2005. Diccionario de símbolos. Madrid: Siruela.

Clegg, J. 1995. About pictures of echidnas and cats. Rock Art Research 12: 11-13.

Conkey, M. 2006. Style, design and function. En Handbook of material culture, C. Tilley, W. Keane, S. Kuechler-Fodgen, M. Rowlands \& P. Spyer, Eds., pp. 355-372. Londres: SAGE.

Conkey, M. \& Hastorf, C. 1990. The uses of style in archaeology. Cambridge: Cambridge University Press.

Criado, F. 1991. Construcción social del espacio y reconstrucción arqueológica del paisaje. Boletín de Antropología Americana 24: 5-29.

Criado, F. 1993. Visibilidad e interpretación del registro arqueológico. Trabajos de Prehistoria 50: 39-56.

Dobrez, P. 2013. The case for hand stencils and prints as proprio-performative. Arts 2 (4): 273-327.

Domingo-SAnz, I., Fiore, D. \& MAY, S. 2008. Archaeologies of art: time, place and identity in rock art, portable art and body art. En Archaeologies of art: time, place and identity. I. Domingo-Sanz, D. Fiore \& S. May, Eds., pp. 15-28. Walnut Creek: Left Coast Press.

Domingo-SAnZ, I. \& MAY, S. 2008. La pintura y su simbología en las comunidades de cazadores-recolectores de la tierra de Arnhem (Territoriodel Norte, Australlia). En Mundos tribales: una visión etnoarqueológica, J. Salazar, I. Domingo,
J. Azkárraga \& H. Bonet, Eds., pp. 78-91. Valencia: Museu de Prehistòria.

EARLE, T. 1990. Style and iconography as legitimation in complex chiefdoms. En The uses of style in archaeology, M. Conkey \& C. Hastorf, Eds., pp. 73-81. Cambridge: Cambridge University Press.

FIORE, D. 2009. La materialidad del arte: modelos económicos, tecnológicos y cognitivos-visuales. En Perspectivas actuales en arqueología argentina, R. Barberena, K. Borrazzo \& L. Borrero, Eds., pp. 121-154. Buenos Aires: Instituto Multidisciplinario de Historia y Ciencias Humanas.

Fuentes, F. \& Mena, F. 2010. Estacionalidad y movilidad en cazadores-recolectores. El caso de Cueva Las Guanacas (valle del río Ibáñez, Aysén, Chile). Werkén 13: 359-370.

Gamble, C. 1990. Demografía y estilo. En El poblamiento paleolitico de Europa, C. Gamble, Ed., pp. 332-371. Barcelona: Crítica.

Gómez, M. L. 2016. Aprovechamiento de recursos líticos en el valle del río Ibáñez, Región de Aysén, Chile (Andes centropatagónicos). En Arqueología de Patagonia: de mar a mar, F. Mena, Ed., pp. 34-47. Coyhaique: CIEP.

Gradin, C. 1983. El arte rupestre de la cuenca del río Pinturas, Provincia de Santa Cruz, República Argentina. Acta Prehistórica 2: 87-148.

Gradin, C. \& Aguerre, A. 1994. Contribución a la arqueología del río Pinturas, provincia de Santa Cruz. Concepción del Uruguay: Búsqueda de AYLLU.

Gradin, C., Aschero, C. \& Aguerre, A. 1979. Arqueología del área río Pinturas. Relaciones de la Sociedad Argentina de Antropología 13: 183-225.

Gradin, C., Aschero, C. \& Aguerre, A. 1987. Primeros niveles culturales en el área río Pinturas (Provincia de Santa Cruz, Argentina). Estudios Atacameños 8: 118-141.

Greer, M. \& Greer, J. 1999. Handprints in Montana rock art. The Plains Anthropologist 44 (167): 59-71.

GunN, R. 2006. Hand sizes in rock art: interpreting the measurements of hand stencils and prints. Rock Art Research 23 (1): $97-112$.

Halbwachs, M. 1968. La mémorie collective. París: Presses Universitaires de France.

Hegmon, M. 1992. Archaeological research on style. Annual Review of Anthropology 21 (1): 517-536.

Hernando, A. 2002. Arqueología de la identidad. Madrid: AKAL.

HodDer, I. 1978. The maintenance of group identities in the Beringo district, west Kenya. En Social organisation and settlement: contributions from anthropology, archaeology and geography, I. Green, C. Haselgrove \& M. Spriggs, Eds., pp. 47-74. Oxford: Bar International Series.

Hodder, I. 1990. Style as historical quality. En The uses of style in archaeology, M. Conkey \& C. Hastorf, Eds., pp. 44-51. Cambridge: Cambridge University Press.

INGOLD, T. 1987. Territoriality and tenure: the appropriation of space in hunting and gathering societies. En The appropriation of nature: essays on human ecology and social 
relations, T. Ingold, Ed., pp. 130-164. Iowa: University of Iowa Press.

Labarca, R., Fuentes, F. \& Mena, F. 2008. Los conjuntos faunísticos pleistocénicos de Cueva Las Guanacas (Región de Aysén, Patagonia chilena): alcances taxonómicos y tafonómicos. Magallania 36 (2): 123-142.

LAMING-EMPERAIRE, A. 1966. Remarques sur lart rupestre du sud du Brésil. En Actas y Memorias del XXXVII Congreso Internacional de Americanistas, Tomo 2, pp. 495-503. Buenos Aires.

LAYTON, R. 1992. Australian rock art: a new synthesis. Cambridge: Cambridge University Press.

Lucero, V. \& Mena, F. 1994. Sitio arqueológico RI-1: Monumento Nacional Las Manos de Cerro Castillo (río Ibáñez, XI Región). Tierradentro 10: 6-16.

Lucero, V. \& Mena, F. 2000. Arte rupestre del río Ibáñez (XI Región): un análisis cuantitativo exploratorio. En Desde el país de los gigantes, perspectivas arqueológicas en Patagonia, Actas de las IV Jornadas de Arqueología de la Patagonia, Tomo 1, pp. 415-427. Río Gallegos: Universidad Nacional de la Patagonia Austral.

Martel, A., Rodríguez, S. \& Del Bel, E. 2012. Arte rupestre y espacios de memoria: representaciones del sitio Confluencia (Antofagasta de la Sierra, Catamarca, Argentina). Revista de Antropología 25: 121-162.

MAY, S. 2009. Learning art, learning culture: art, education, and the formation of new artistic identities in Arnhem Land, Australia. En Archaeologies of art: time, place and identity, I. Domingo-Sanz, D. Fiore \& S. May, Eds., pp. 171-194. Walnut Creek: Left Coast Press.

McDonald, J. 2000. Media and social context: influences on stylistic communication networks in prehistoric Sydney. Australian Archaeology 51: 54-63.

MenA, F. 1983. Excavaciones arqueológicas en Cueva Las Guanacas (RI-16) xi Región. Anales del Instituto de la Patagonia 14: 65-75.

Mena, F. 1989. Hacia un panorama del registro arqueológico regional: promesas y "frustraciones". Arqueología Contemporánea 2: 31-62.

Mena, F. 1990. Prehistoric settlement patterns and resources distribution in the middle río Ibáñez, central Patagonia. The Explorers Journal 2: 84-87.

MenA, F. 1992. Mandíbulas y maxilares: un primer acercamiento a los conjuntos arqueofaunísticos del Alero Fontana (RI22, xi Región). Boletín del Museo Nacional de Historia Natural 43: 179-191.

Mena, F. 2000. Un panorama de la prehistoria de Aysén oriental: estado del conocimiento a fines del siglo. Serie Antropología de la Universidad San Sebastián 2: 21-41.

MenA, F. 2016a. Sistema de movilidad restringida y circulación en el valle del río Ibáñez, Andes centro-patagónicos, Chile. En Arqueología de Patagonia: de mar a mar, F. Mena, Ed., pp. 48-57. Coyhaique: CIEP.

MenA, F. 2016b. Nuevas investigaciones arqueológicas en río Ibáñez: excavaciones en RI-23. Aysenología 2 (1): 5-15.
Mena, F. \& Buratovic, C. 1997. Cenizas volcánicas y procesos de formación de sitios arqueológicos: un estudio actualístico preliminar en la Patagonia central chilena. Chungara 29: 181-193.

Mena, F., García, C. \& Silva, E. 2015. Ms. Nuevas investigaciones arqueológicas en río Ibáñez (XI Región, Chile): excavaciones en RI-23. Informe final. Proyecto FONDECYT 1110556.

Mena, F. \& Lucero, V. 1998. Para humanizar la inmensidad: pinturas rupestres en el curso medio del río Ibáñez, Andes Patagónicos/xi Región, Chile. Arkinka 35: 72-83.

Mena, F. \& Lucero, V. 2015. Ms. Nuevas investigaciones arqueológicas en río Ibáñez: excavaciones en RI-6 (este) y RI-23. Informe final. Proyecto FONDECYT 1110556.

Mena, F., Lucero, V., Artigas, D. \& Villagra, D. 2013. Ms. Sistematizando la arqueología del Ibáñez medio: ¿subsistema cultural o adaptación particular de un sistema más amplio? Informe de avance Etapa 2012. Proyecto FONDECYT 1110556.

Mena, F. \& Ocampo, C. 1993. Distribución, localización y caracterización de sitios arqueológicos en el río Ibáñez (XI Región). Actas del XII Congreso Nacional de Arqueología Chilena 1: 33-58.

Méndez, C. \& Reyes, O. 2006. Nuevos datos de la ocupación humana en la transición bosque estepa en Patagonia: Alero Las Quemas (comuna de Lago Verde, xi Región de Aysén). Magallania 34: 161-165.

Moore, D. R. 1977. The hand stencil as symbol. En Form in indigenous art: schematisation in the art of aboriginal australia and prehistoric Europe (Prehistory and Material Culture Series, No 13), P. J. Ucko, Ed., pp. 318-324. Canberra: Australian Institute of Aboriginal Studies.

Mulvaney, K. 1996. What to do on a rainy day: reminiscences of Mirriuwung and Gadjerong artists. Rock Art Research 13 (1): 3-20.

Muñoz, C. 2013. Caracterización de los sitios ubicados en el río Ibáñez, xi Región de Aysén, Chile: una aproximación a la relación arte rupestre-asentamiento. En Tendencias teórico-metodológicas de estudio en la arqueología de la Patagonia, A. F. Zangrando, R. Barberena, A. Gil, G. Neme, M. Giardina, L. Luna, C. Otaola, S. Paulides, L. Salgán \& A. Tivoli, Eds., pp. 203-212. Mendoza: Museo Historia Natural San Rafael.

Muñoz, C. \& ARTigas, D. 2016. Dar la mano y tomarse el todo: los sitios rupestres del Ibáñez medio como ventanas de un mundo abierto a los sistemas culturales amplios. En Arqueología de Patagonia: de mar a mar, F. Mena, Ed., pp. 58-66. Coyhaique: CIEP.

SACKetT, J. R. 1982. Approaches to style in lithic archaeology. Journal of Anthropological Archaeology 1 (1): 59-112.

SACKeTT, J. R. 1985. Style and ethnicity in the Kalahari: a reply to Wiessner. American Antiquity 50 (1): 154-159.

SACKeTT, J. R. 1986. Isochrestism and style: a clarification. Journal of Anthropological Archaeology 5 (3): 266-277.

Shanks, M. \& Tilley, C. 1987. Social theory and archaeology. Cambridge: Polity Press. 
Smith, C. 1992. Colonising with style: reviewing the nexus between rock art, territoriality and the colonisation and occupation of Sahul. Australian Archaeology 34: 34-42.

Sмiтн, C. 1994. Situating style. An ethnoarchaeological study of social and material context in an Australian aboriginal artistic system. Tesis para optar el grado de Doctora, University of New England.

Steelman, K. 2014. Ms. Radiocarbon dating Chilean Patagonia rock paintings. Informe de avance, Proyecto FONDECYT 1110556.

TAçON, P. 1989. From the "dreamtime" to the present: the changing role of aboriginal rock paintings in western Arnhem Land, Australia. Canadian Journal of Native Studies 9 (2): 317-319.

TAçON, P. 1994. Socialising landscapes: the long-term implications of signs, symbols and marks on the land. Archaeology in Oceania 29 (3): 117-129.

TAÇON, P. \& CHIPPINDALE, C. 1998. Introduction: an archaeology of rock-art through informed methods and formal methods, En Archaeology of rock art, C. Chippindale \& P. Taçon, Eds., pp. 1-10. Cambridge: Cambridge University Press.

Thomas, J. 1995. Time, culture and identity. an interpretative archaeology. Londres: Routledge.
Troncoso, A. 1998. Petroglifos, agua y visibilidad: el arte rupestre y la apropiación del espacio en el curso superior del río Putaendo, Chile. Valles, Revista de Estudios Regionales 4: 127-137.

Troncoso, A. 2003. Proposición de estilos para el arte rupestre del valle de Putaendo, curso superior del río Aconcagua. Chungara 35 (2): 209-231.

Velásquez, H. \& Trejo, V. 2003. Alero Fontana: aprovechamiento específico del huemul. En Actas del XVI Congreso Nacional de Arqueología Chilena. Tomo 1, pp. 557-565. Concepción: Caparate.

Wiessner, P. 1983. Style and social information in Kalahari San projectile points. American Antiquity 48 (2): 253-276.

WIESSNER, P. 1984. Reconsidering the behavioral basis for style: a case study among the Kalahari San. Journal of Anthropological Archaeology 3 (3): 190-234.

WIESSNER, P. 1990. Is there a unity to style? En The uses of style in archaeology, M. Conkey \& C. Hastorf, Eds., pp. 105-122. Cambridge: Cambridge University Press.

Wовsт, H. M. 1977. Stylistic behaviour and information exchange. En For the Director: research essays in honour of James B. Griffin, C. Cleland, Ed., pp. 317-342. Ann Arbor: Museum of Anthropology, University of Michigan. 